\title{
Rare Case of Ruptured Sinus of Valsalva: Ruptured Into Left Ventricular Cavity
}

\author{
SDM Taimur, SR Khan, MR Karim, MH Rahman \\ Department of Cardiology, Ibrahim Cardiac Hospital and Research Institute, Dhaka
}

Key Words:

Rupture sinus of valsalva; Aneurysm; Left ventricle.

\begin{abstract}
:
Rupture sinus of Valsalva is a relatively rare condition. We report a rare case of ruptured left sinus of valsalva with aneurysm, presenting with acute left ventricular failure. Transthoracic echocardiography showed an aneurysmal dilatation of the base of interventricular septum and part of the aortic root and a marked turbulent flow from the aortic root to the left ventricle with a continuous systolodiastolic shunting. The patient underwent successful repair of ruptured sinus of valsulva with closure of fistula. During Ventriculotomy the defect was repaired using pledgeted 5/ 0 prolene interrupted sutures and pericardial patch.
\end{abstract}

(Cardiovasc. j. 2011; 4(1): 96-98)

\section{Introduction:}

Though well known, ruptured sinus of Valsalva (RSOV) aneurysms are rare comprising 0.3-3.56\% of all congenital heart diseases. ${ }^{1}$ They are thin walled outpouchings of the sinus of Valsalva and may be tubular or saccular in shape. The right sinus of Valsalva is most commonly involved and usually ruptures into right heart chambers. Uncommonly they rupture into left heart chambers (left atrium, left ventricle), pulmonary artery, interventricular septum or the pericardial cavity. ${ }^{2,3}$ Rupture into the left ventricle (LV) is very rare. ${ }^{4,5}$ We report a middle age male patient who was diagnosed to have a large aneurysm of left sinus of Valsalva with rupture into left ventricle. To our knowledge, this has not been reported preveously.

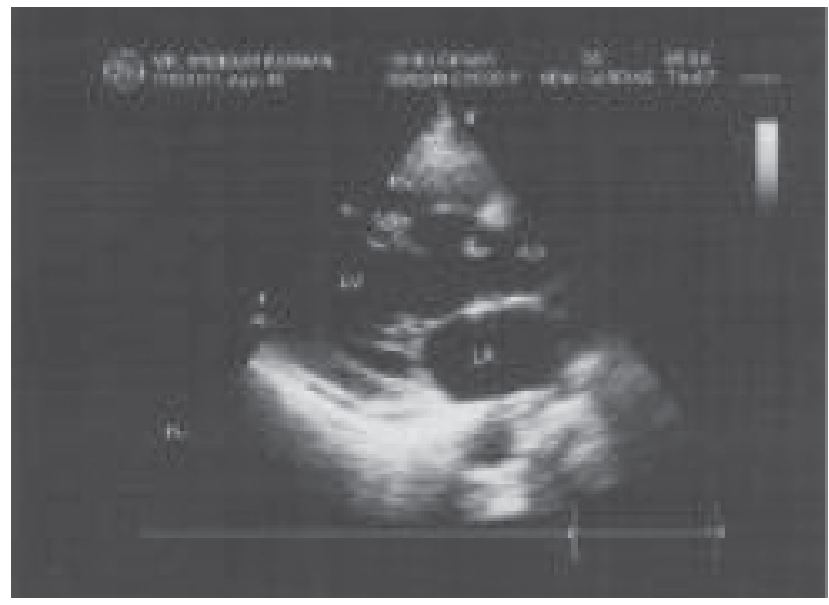

\section{Case Report:}

A 49-year-old normotensive nondiabetic ex-smoker man was admitted in to the hospital following a 3week period of progressive dyspnea accompanied by acute orthopnea with palpitation. He also complains occational fever and joint pain for one year. The blood pressure measured was 110/60 $\mathrm{mmHg}$ and the pulse was regular with a rate of 90 beats per minute. The resting ECG showed sinus tachycardia and left ventricular hypertrophy. Auscultatory examination of the chest revealed a early diastolic murmur at the left sternal border. Bilateral basal crepitation was present in both lung fields. Transthoracic echocardiography was performed and demonstrated that there was eccentric severe aortic regurgitation with aneurysmatic dilatation of the membranous part

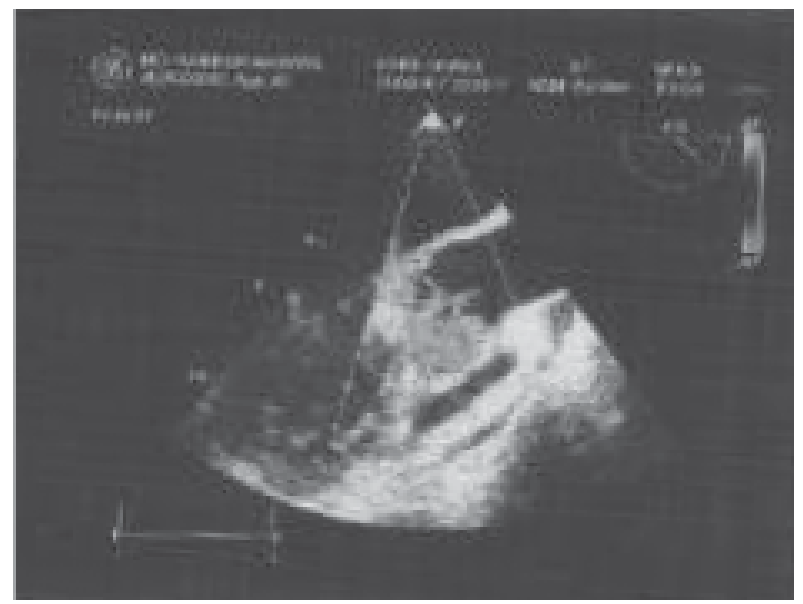

Fig 1: (a-Left panel) Transthorasic Echo: long axis view showing the aneurysm of the left coronary cusp. $L A=L e f t$ atrium, $L V=$ Left ventricle, $R V=$ Right ventricle, $A O=$ Aorta. (b-Right panel) Transthorasic Echo: showing jet flow between aorta \& left ventricle.

Address of Correspondence : Dr. Syed Dawood Md. Taimur, Department of Cardiology, Ibrahim Cardiac Hospital \& Reseach Institute. Email:dr.sdmtaimur@yahoo.com 

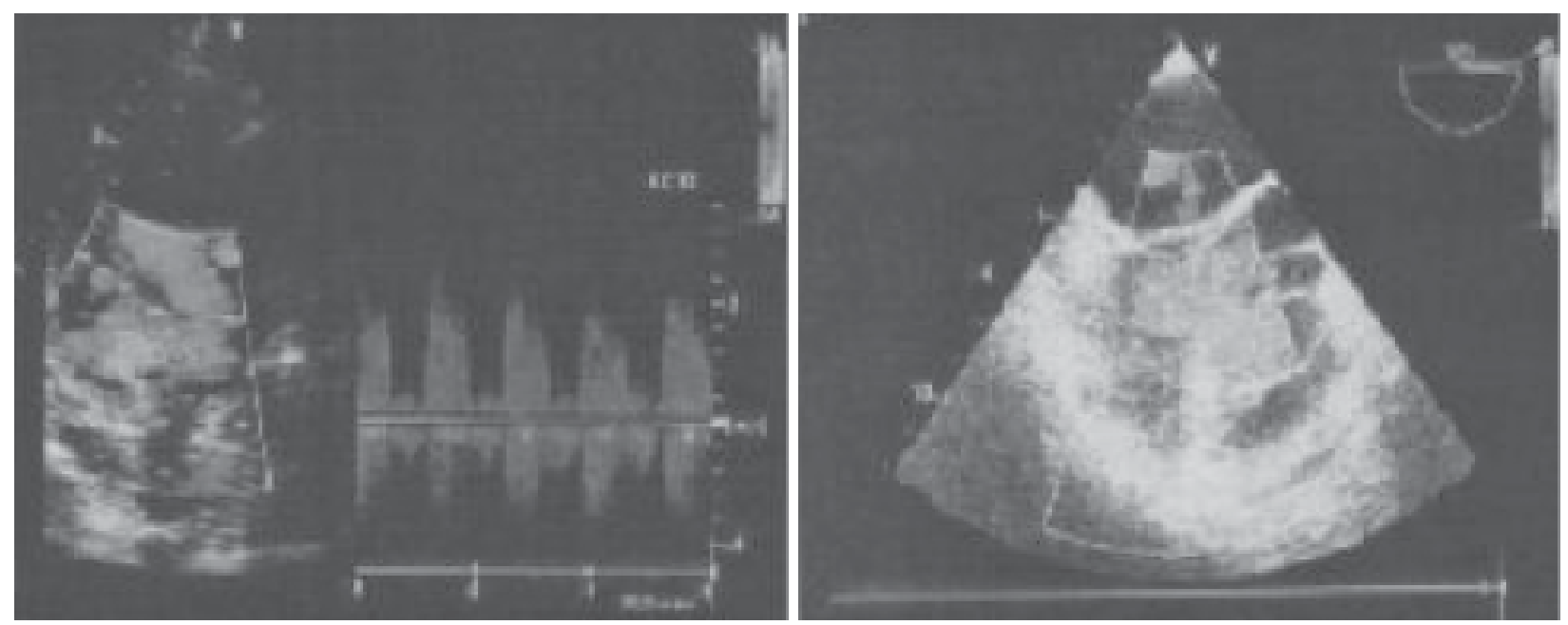

Fig.-2:(a-Left panel) Transthorasic Echo showing a diastolic pattern between aorta \& aneurysm. 2(bRight panel) Transesophageal Echocardiography shows aorta with aneurysm.
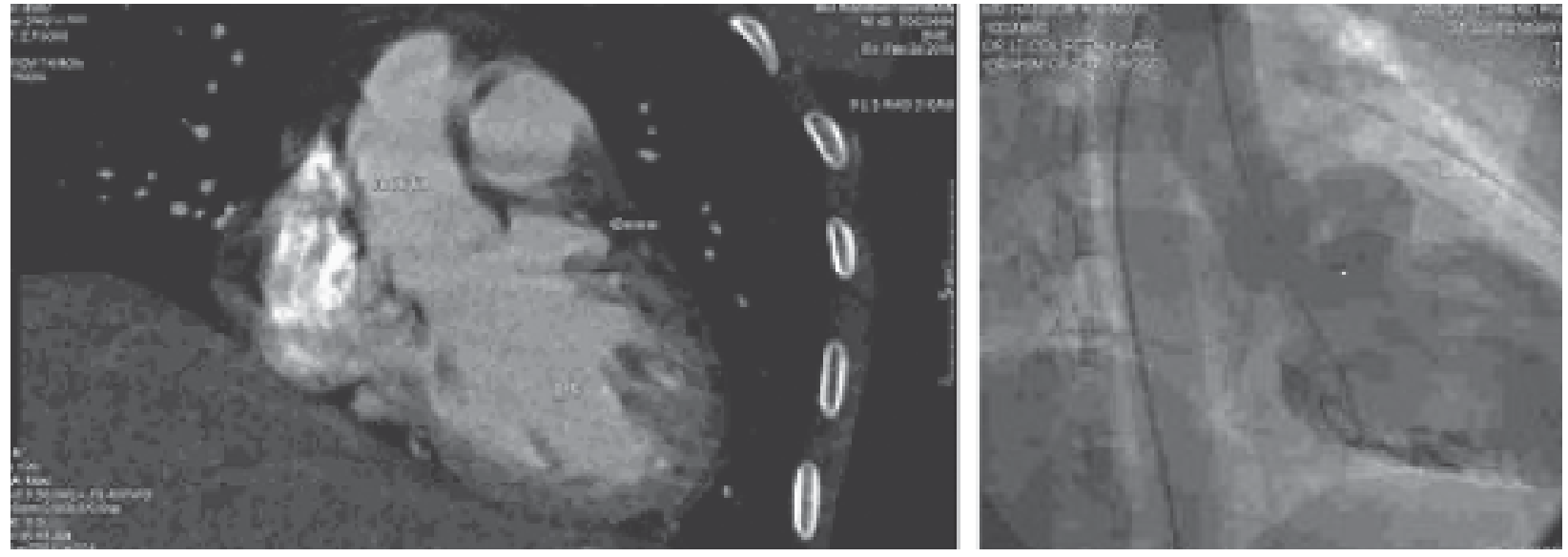

Fig.-3:(a-Left)CT coronary angiogram revealed outpouching was noted just below root of aorta,there was suspected communication between ascending aorta and main pulmonary artery(MPA). (b-Right) CAG: Aortography showed severe eccentric aortic regurgitation.LV graphy showed LV basal aneurismal dilatation.

of interventriclar septum and part of the aortic root. Rupture sinus of valsalva with mosaic flow was seen passing from aorta to a cavity bounded by sac-like structure between left ventricle to right ventricle, sac was present below the aorta in between left ventricle to right ventricle. Transesophageal echocardiography showed aortic root communicating with base of interventricular septum (IVS) along with sac like structure which ultimately communicates with left ventricle. CT coronary angiogram revealed outpouching just below the root of aorta and there was suspected communication between ascending aorta and main pulmonary artery(MPA).
Coronary angiogram revealed normal epicardial coronary arteries; aortography showed severe eccentric aortic regurgitation..LV graphy showed LV basal aneurysmal dilatation. No communication between aorta and pulmonary trunk was seen. The patient was scheduled for surgery. Aortic leaflets were intact and normal. Left and noncoronary sinuses were normal. Left aortic sinus opened into a sac within the interventricular septum. There were no exit point seen from within the aortic valve and indirect evidence of exit point in LV .Opening in sinus was closed with interrupted pledgeted $5 / 0$ proline and a pericardial patch. He was rapidly weaned from $\mathrm{CPB}$ on no 
inotropic support. He was transferred to ICU and was extubated six hours later. On postoperative day one, the chest tubes were removed and she was transferred to Cardiac Surgery unit. He was discharged on postoperative day seven.

\section{Discussion:}

The earliest descriptions of sinus of Valsalva were in the reports of Hope and Thurman. ${ }^{6,7}$ Later, Abbott described this malformation as congenital and not acquired in origin. ${ }^{8}$ Most aneurysms are congenital in origin but they may be seen after bacterial endocarditis, atherosclerosis or chest trauma. ${ }^{2,9}$ Aneurysms of sinus of Valsalva are thought to result from the absence of normal elastic and muscular tissue, which leads to thinning of the wall of the aortic sinus. ${ }^{4-7}$ In a study of 332 patients collected from Western and Oriental literature by Chu et al, pathological rupture of a sinus of Valsalva most frequently involved the right sinus $(76.8 \%)$, followed by the noncoronary $(20.2 \%)$, and least commonly, the left sinus of Valsalva (3\%). ${ }^{1}$ On

reviewing the English literature we could find only 26 cases of RSOV ruptured into the left ventricle and out of them only 3 arose from a left sinus of Valsalva aneurysm. ${ }^{5}$ In all of them, the aneurysm was repaired along with aortic valve replacement.

Presentation of sinus of Valsalva aneurysm is varied. ${ }^{1-5}$ With rupture, the presentation is acute with chest pain and dyspnea. Chest pain is due to acute AR from the ruptured sinus of Valsalva, frank or dynamic coronary artery compression, or dissection into a coronary artery. Unruptured sinus of Valsalva aneurysms are usually asymtomatic but may sometimes present as right ventricular outflow tract obstruction when they bulge into right ventricular outflow tract, or subaortic stenosis when they bulge into the left

ventricular outflow tract. Rarely, complete heart block occurs when it erodes into the interventricular septum. ${ }^{10-12}$

Associated heart defects that have been reported are ventricular septal defect (in about 50\% of cases), pulmonary stenosis, tetralogy of Fallot, coarctation of aorta, bicuspid aortic valve, valvular and supravalvular aortic stenosis, left superior vena cava and one case report of anomalous origin of left coronary artery from pulmonary artery. ${ }^{2}$
Initially, angiography was the gold standard for the diagnosis but now, noninvasive modes of diagnosis such as echocardiography (transthoracic, transesophageal), spiral computed tomography and cardiac magnetic resonance imaging have taken over as preferred investigations. In our case we were able to delineate the detailed anatomy by transthoracic echocardiography and the patient underwent surgery repair of rupture sinus valsalva.

\section{Conflict of Interest : None.}

\section{References:}

1. Chu SH, Hung CR, How SS, Chang H, Wang SS, Tsai CH, Liau CS, Tseng CD, Tseng YZ, Lee YT. Ruptured aneurysms of sinus of Valsalva in Oriental patients. $J$ Thoracic Cardiovasc Surg 1990; 99: 288-298.

2. Freedom RM, Yoo SJ. Sinus of Valsalva aneurysm In: The Natural and Modified History of Congenital Heart Disease. Eds: Freedom RM, Yoo SJ,Mikailian H,William WG. 1st Edition. New York: Blackwell Publishing, 2004:183-185.

3. Park SH, Jung HS, Mina YU, Min SK, Ahn JH, Kim Y. Left Valsalva sinus aneurysm rupture into left atrium and aortic valve prolapse confirmed with transesophageal Echocardiography. $J$ Am Soc Echocardiogr 2007; 20:1010.e3-e6.

4. Glock Y, Ferrarini JM, Puel J, Fauvel JM, Bounhoure JP, Peul P. Isolated aneurysm of the left sinus of Valsalva. J Cardiovasc Surg 1990; 31: 235-238.

5. Kucukoglu S, Ural E, Mutlu H, Ural D, Sonmez B, Uner S. Ruptured aneurysm of the sinus of Valsalva into the left ventricle; a case report and review of literature. J Am Soc Echocardiogr 1997; 10: 862-865.

6. Hope J. A Treatise on the Disease of the Heart and Great Vessels, 3rd edn. London: W Kidd,1835:432-434.

7. Thurman J. On aneurisms and especially varicose aneurysms of the ascending aorta, and sinuses of Valsalva, with cases. Med Chir Tr 1840;323-384.

8. Aboot ME. Clinical and development study of a case of ruptured aneurysm of the right anterior aortic sinus of Valsalva .In: Contributions to Medical and Biological Research, Vol. 2 New York:Hoeber PB, 1919: 899-914.

9. Vereckei A, Vandor L, Halasz J, Karadi I, Maria L. Infective endocarditis resulting in rupture of sinus of Valsalva with a rupture site communicating with both the right atrium and right ventricle.J Am Soc Echocardiogr 2004; 17: 995-997.

10. Venning GR.Aneurysm of the sinuses of Valsalva.Am Heart J 1951;42:57-69.

11. McGoon DC,Edwards JE,Kirlin JW.Surgical treatment of ruptured aneurysm of aortic sinus.Ann Surg 1958; 147:387-390.

12. Durgaprasad R, Gangapatnam S, Rao P, Maddirala P, Sonuguri G. Unruptured Sinus of Valsalva Aneurysms Manifesting as Complete Heart Block. Asian Cardiovasc Thorac Ann 2005; 13:283-286. 